\title{
1 Synchronised brood transport by ants occurs without
}

\section{2 communication}

Danielle P. Mersch ${ }^{1, *}$, Jean-Pierre Eckmann ${ }^{2}$, Alessandro Crespi $^{3}$, Laurent Keller $^{1}$

$6 \quad{ }^{1}$ Department of Ecology and Evolution, University of Lausanne, Switzerland

$7 \quad{ }^{2}$ Département de Physique Théorique et Section des Mathématiques, Université de

8 Genève, Switzerland

$9 \quad{ }^{3}$ Biorobotics Laboratory, Ecole polytechnique fédérale de Lausanne, Switzerland

*corresponding authors: danielle.mersch@gmail.com , laurent.keller@unil.ch

15 Collective behaviours in societies such as those formed by ants are thought to be the result of distributed mechanisms of information processing and direct decision-making by well-informed individuals, but their relative importance remains unclear. Here we tracked all ants and brood movements to investigate the decision strategy underlying brood transport in nests of the ant Camponotus fellah. Changes in environmental conditions induced workers to quickly

21 transport the brood to a preferred location. Only a minority of the workers, mainly nurses, participated in this task. Using a large number of statistical tests we could further show that these transporters omitted to recruit help, and relied only on private information rather than information obtained from other workers. This reveals that synchronised group behaviour, often suggestive of coordinated actions among workers, can also occur in the complete absence of communication.

30 The success of group actions frequently relies on communication between

31 individuals. Communication is manifest in animal groups as different as jellyfish

32 that use bioluminescence to locate each other and team up ${ }^{1}$, prairie dogs that call 
33 to warn their family of predators ${ }^{2}$ and honeybees that use waggle dance to signal

34 a food source to nest mates ${ }^{3,4}$. In all these cases communication serves to 35 enhance the efficiency and safety of the group. However, communication is 36 complex. It requires that the sender recognizes the appropriate circumstances and produces a correct signal, and that the receivers are able to understand the signal and react appropriately. These inherent difficulties constrain when and under what conditions groups of animals might communicate.

41 In ant societies communication is widespread and individuals make use of an array of 42 olfactory, vibrational and tactile communication strategies. Therefore, communication 43 is often assumed to be underlying all group behaviours ${ }^{5,6,7,8,9,10}$. Ants optimize foraging 44 by creating pheromone trails ${ }^{11,12}$, and by recruiting help to retrieve food through tandem runs, a method whereby a knowledgeable ant induces a naive ant through tactile and chemical signals to follow it $^{13}$. In emergencies, ants release highly volatile alarm pheromones ${ }^{11}$. If a nest is destroyed knowledgeable ants first lead tandem runs to new nest sites before switching to brood transport ${ }^{14}$. In all these instances communication is manifest and beneficial to the society. Pheromone trails and tandem recruitment reduce the risks of random food searches and ensure that a sufficient number of workers locate and retrieve food before it disappears, thereby enhancing the colony's chances of survival and reproduction. Similarly in emergencies the survival of the colony is at stake. Alarm pheromones ensure that workers are alerted and leave the nest ${ }^{15}$ for fight or flight. Tandem runs ensure that a sufficient number of workers know the location of a safe alternative nest before evacuating brood ${ }^{9}$. However, there is a range of other group behaviours such as nest construction or brood relocation where the advantages of communication are less apparent. For example, many ant species regularly move brood within a nest and between nests to raise offspring under optimal temperature and humidity ${ }^{16,17,18,19,20}$. Such controlled responses to environmental variables are a central part of colony organisation in social

61 insects because they have direct impacts on colony growth, metabolic expenditure, survival and reproduction ${ }^{19,20,21}$.

64 In this study we conduct a detailed analysis of brood transport in the ant Camponotus 
66 changes in environmental conditions. We took advantage of the fortuitous observation that workers moved the brood in response to environmental changes in three colonies (colony size $=197,192$, and 206 workers, brood items=150, 60 and 35) to investigate whether workers communicate about observed changes in local conditions. In $C$. fellah, as in most other ants, workers quickly respond to environmental changes to move the brood to the nest regions with the best conditions $22,23,24,25$.

\section{Results}

\section{Colonies transport brood in synchrony}

75 In each of the three colonies, and each of the nights, workers responded to the environmental change, initiating brood transport $22.4 \pm 6.2$ minutes (mean \pm SEM) after the light was turned off in the tunnel (Fig. 1). There were neither consistent differences across colonies, nor a change in the response delay over the three days

79 (ANCOVA, colony: $\mathrm{F}=0.9, \mathrm{p}=0.37$; day: $\mathrm{F}=0.77, \mathrm{p}=0.41$; interaction colony*day:

$80 \mathrm{~F}=0.41, \mathrm{p}=0.69)$. On average workers took $160.0 \pm 48.0$ minutes to move all the brood

81 from the nest to the tunnel once transport was initiated. Workers also performed this 82 task in synchrony with multiple workers transporting in parallel during $66.1 \pm 28.0 \%$ of 83 the time. The average time taken by a worker to transport one brood item was $84 \quad 36.7 \pm 4.0$ seconds (see Supplementary Video 1). Workers that transported more brood 85 items were faster to transport brood than those transporting fewer brood items 86 (Spearman rank correlation: $\varrho=-0.51, \mathrm{p}<0.0001$; Supplementary Fig. 2). There were 87 again neither significant differences across colonies, nor over days, in the time 88 required to transport all the brood (ANCOVA on log-transformed duration: colony: $\mathrm{F}=1.5, \mathrm{p}=0.31$; day: $\mathrm{F}=1.3, \mathrm{p}=0.24$; colony*day: $\mathrm{F}=1.2, \mathrm{p}=0.40)$. 

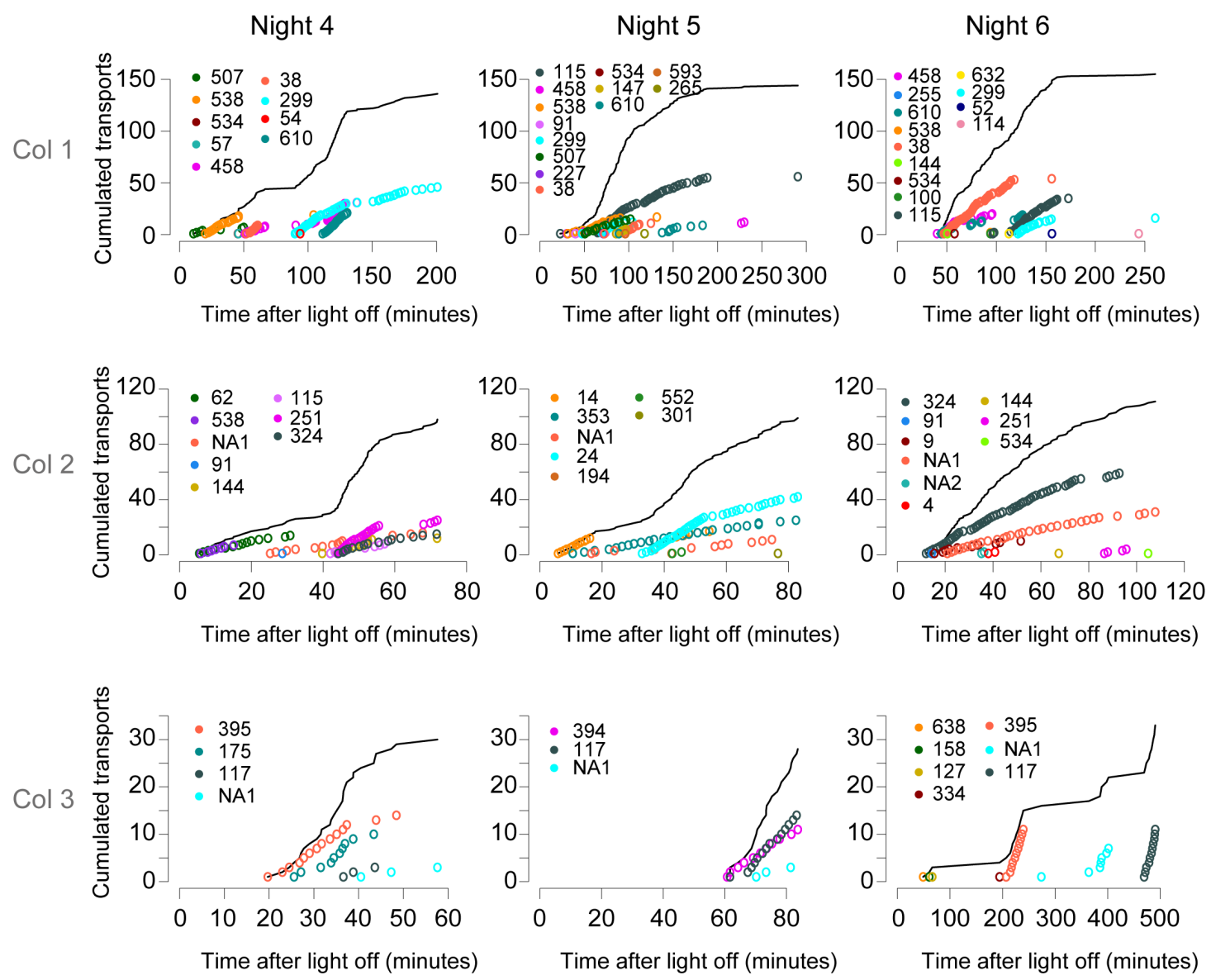

Fig 1. Brood transport dynamics on three consecutive days in three colonies. The black line indicates the cumulated number of brood transports to the tunnel of all workers. Each coloured circle represents a single brood transport event by one worker, and data are shown as

\section{A small minority of a colony's workforce transports brood}

The number of workers involved in brood transport was consistently low, with only $8.1 \pm 1.1$ workers $(4.1 \% \pm 0.6 \%$ of the workforce) participating in brood transport on any given day in any given colony (Fig. 2). Colonies did not differ in the distribution of the workload among workers, and there was no significant change over days in the way the workload was distributed among transporters (ANCOVA: colony: $\mathrm{F}=0.40$ $\mathrm{p}=0.67$; day: $\mathrm{F}=0.15 \mathrm{p}=0.86$; colony*day: $\mathrm{F}=0.14, \mathrm{p}=0.97$ ). However, there was variation among transporters in their relative contribution with the notable effect that more than $80 \%$ of all brood transports were performed by less than $1.8 \%$ of all workers. In addition, there was also a high worker turnover with $66.9 \pm 5.2 \%$ of the transporters working on a single night, while only $18.8 \pm 11.9 \%$ of the transporters worked on all three nights. Importantly, however, the persistent transporters were responsible for $44.3 \pm 25.3 \%$ of all transports while those that worked a single night 
110 contributed together to $24.8 \pm 18.7 \%$ of the transports.

111

Night 4

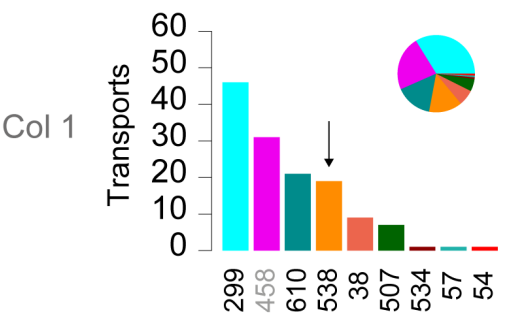

ID of ant
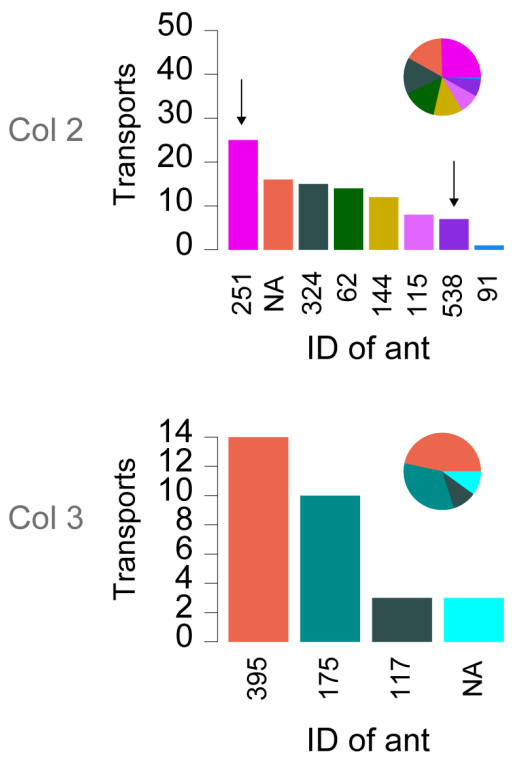

Night 5
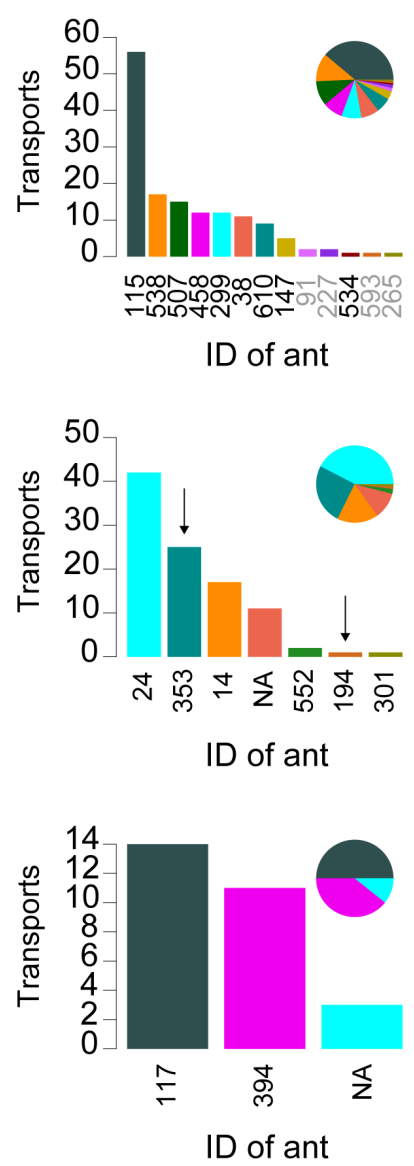

Night 6
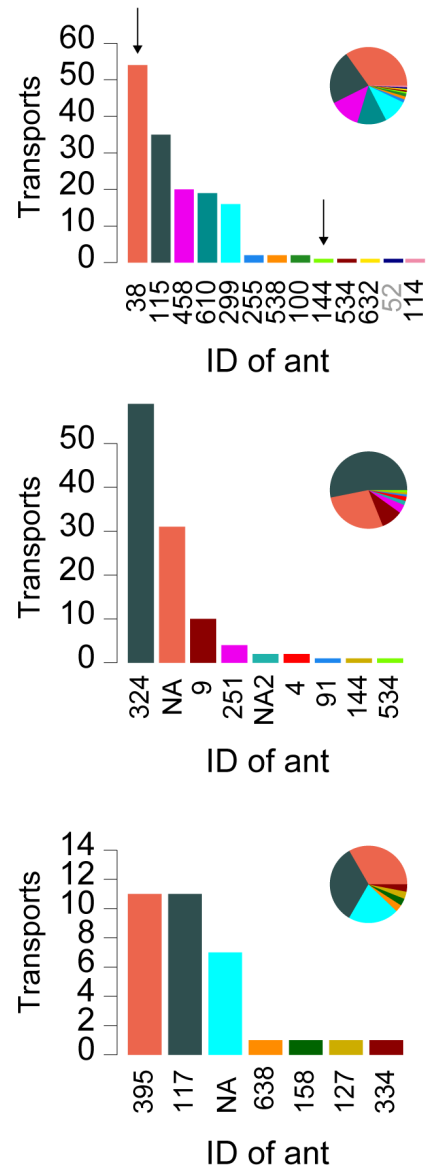

Color ranking based on total transports :

most

fewest

Fig 2. The workload is distributed unevenly among the transporters. Absolute numbers are given in the histogram, and proportions are indicated in the pie chart. Arrows indicate workers that transport without being privately informed (i.e. they had not visited the tunnel before starting to transport). Transporters with ID labels in black are nurses, while those with labels in grey belong to the cleaner or forager groups.

\section{Transporters are nurses}

To determine whether brood transport was preferentially conducted by a specific group of workers, we used the Infomap algorithm ${ }^{26}$ to determine the daily interaction networks of workers and assign each of them to a specific social group ${ }^{27}$. Colonies had on average $55.9 \% \pm 11.3 \%$ nurses, $16.5 \% \pm 4.9 \%$ cleaners and $25.1 \% \pm 7.4 \%$ foragers (Fig. 3). Nurses were 3.8 times more likely to transport than cleaners, and 7.3 more likely to transport than foragers (ANOVA, $\mathrm{F}=51.38$, $\mathrm{p}<0.0002$ ). There was also an effect of age, with transporters being on average younger (83.5 days) than non- 
transporters (119.5 days; Kruskal-Wallis: $\left.\chi^{2}=12.1, \mathrm{p}<0.001\right)$. This effect was due to age differences between the three groups of workers (average age nurses 93.8 days, cleaners 124.2 days, foragers, 159.4 days; Kruskal-Wallis: $\chi^{2}=138.6, p<0.00001$ ).

130 When only nurses were considered, there was no significant age difference between 131 transporters and non-transporters (Kruskal-Wallis: $\chi^{2}=0.81, \mathrm{p}=0.37$; insufficient data was available to conduct similar tests for nest cleaners and foragers).

134

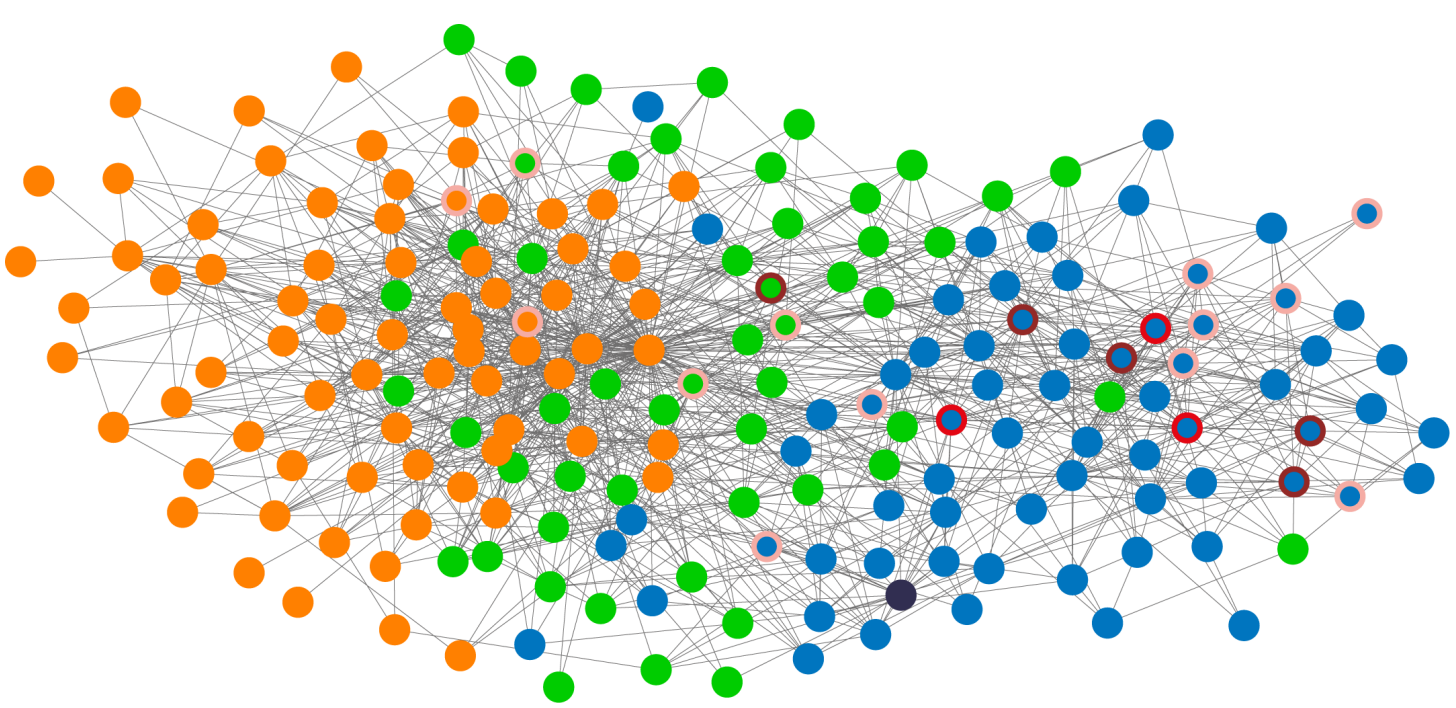

Fig 3. Transporters are mainly nurses. The network shown is that of colony 10 on day 4 . Each node represents a worker, and links between nodes are shown for workers who had more than 10 interactions on that day. The network layout is a spring embedded layout. Group membership is indicated by the node colour: nurse (blue), cleaner (green), forager (orange). Red-shaded circles around nodes highlight transporters, with light red indicating transports on one day, medium red indicating transports on two days, and dark red indicating transports on three days.

\section{Transporters gather information themselves}

To determine whether workers make use of information available to others to decide when to initiate brood transport, we tracked the information available to each worker after the light was turned off. Because the nest entrance was constructed with two $90^{\circ}$ bends and painted in matt black on the inside thereby preventing light from entering the nest, the only means for workers to know whether there was light in the tunnel was to access it. Workers were therefore considered as having private information once they had left the nest for at least three seconds, which is the minimum amount of time an ant needs to reach the tunnel and return to the nest. Ants were considered as socially informed once they interacted with a privately informed worker. 
154 At the start of brood transport, only $31.6 \% \pm 2.9 \%$ of all workers and $37.8 \% \pm 8.7 \%$ of

155 the nurses had private information. However, almost all transports (99.8\%) were 156 performed by privately informed ants. Of the seven workers, which had not visited the 157 tunnel before initiating brood transport, four had transported brood on previous days 158 (Fig. 2). The three remaining workers had visited the tunnel the nights before when it 159 contained brood. Thus, these transporters may have used this information together 160 with circadian timing to initiate transport ${ }^{24,25}$. Therefore, these observations suggest 161 that private information is the primary or only source of information workers use to decide when and where to transport the brood.

\section{Transporters neither communicate nor recruit help}

165 Five lines of evidence further support the view that workers do not use information 166 obtained from other workers to initiate brood transport. First, transporters did not 167 increase their interaction frequency with other workers once it was dark in the tunnel. 168 The rate of interactions in the hour preceding light-off was not significantly different 169 from the rate during the interval between light-off and the first brood transport 170 (Kruskal-Wallis: $\chi^{2}=0.05, p=0.82$; Supplementary Fig. 3). Second, transporters did not 171 change their activity after interacting with a privately informed ant. Their increase in 172 speed - a signature of information transfer in ants ${ }^{28}$ - was similar after interacting 173 with a privately informed or an uninformed ant (Kruskal-Wallis: $\chi^{2}=2.8, p=0.09$, see

174 Supplementary Table 1). Third, brood accumulating in the tunnel did not speed up the 175 recruitment of additional transporters. The average time elapsed before one additional 176 worker contributed to brood transport was $16.6 \pm 3.4 \mathrm{~min}$. The number of workers 177 already participating in brood transport did not alter the time needed to rally an 178 additional worker (Spearman rank correlation: $\varrho=0.06, p=0.60$; Supplementary Fig. 179 4). Fourth, the first interaction with a privately informed ant did not trigger a change 180 in behaviour. After interacting with a privately informed ant, transporters and non181 transporters were neither more likely to approach the nest entrance (Wilcoxon signed 182 rank test: transporters: $\mathrm{V}=1232, \mathrm{p}=0.79$; non-transporters: $\mathrm{V}=495789, \mathrm{p}=0.97$ ) nor to 183 orient towards it (Rao's spacing test for uniformity: transporters: Test 184 Statistic=139.98, $\mathrm{p}>0.05$ with a critical value=148.34; for non-transporters: Test 185 Statistic=134.13, p>0.05 with a critical value=136.94; Fig. 4A, 4B). Simulations were 186 conducted to determine the expected effect if $90 \%, 50 \%, 10 \%$ or $0 \%$ of the 
transporters were able to understand a message that they should go to the tunnel after interacting with a privately informed ant (Fig 4C). These simulations revealed that the observed pattern was consistent with a complete lack of communication between privately informed ants and non-informed transporters. Finally, and most importantly we did not observe any successful recruitment through tandem running although these ants are capable of tandem running (see Supplementary Videos 2, 3).

A

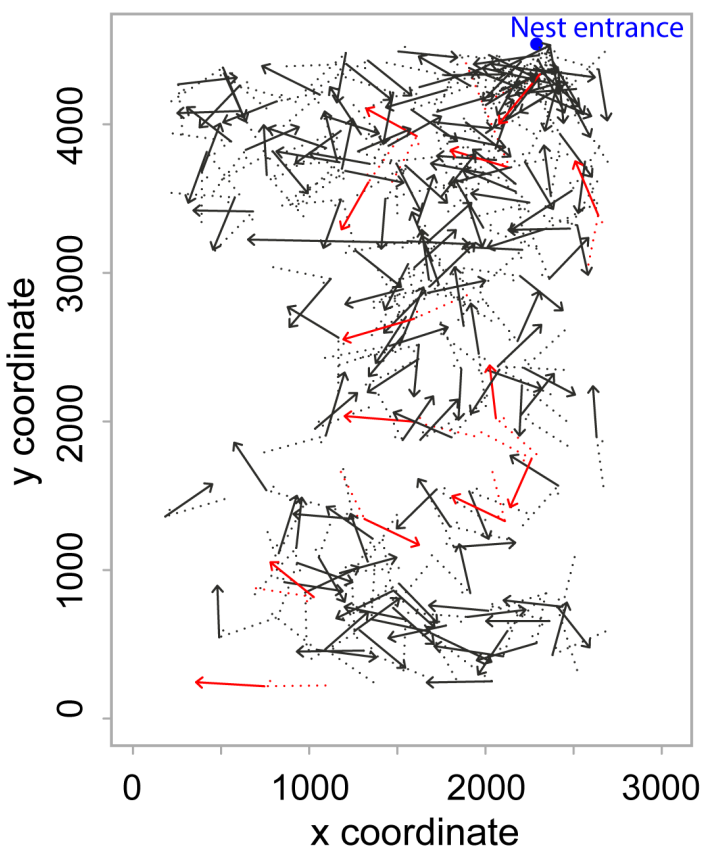

B

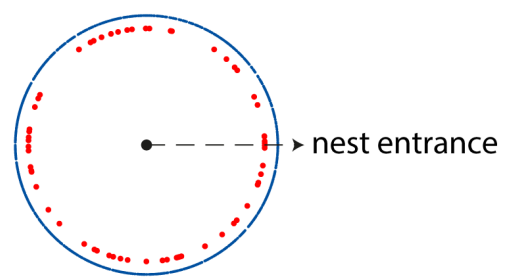

C

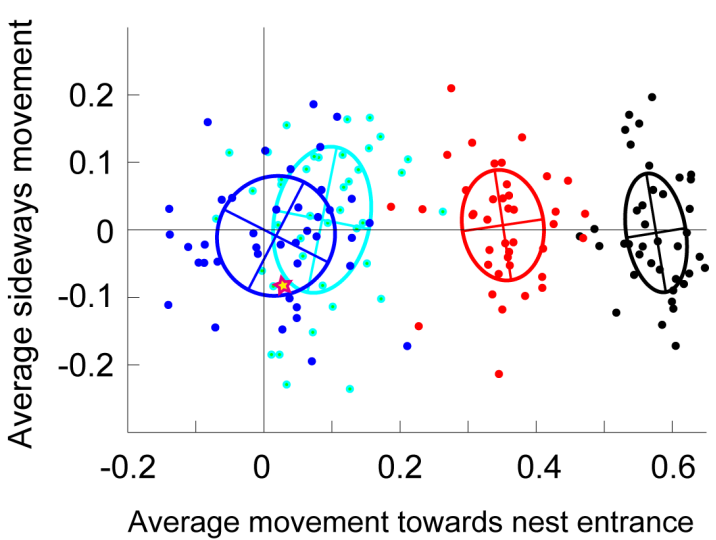

Fig 4. No evidence for communication between workers. (A) Changes of trajectory

\section{Colonies do not use quorum sensing to initiate brood transport}

210 At the colony level there was also no indication of a system of quorum sensing

211 leading to the onset of brood transport. At the time of first transport, the percentage of

212 privately and socially informed workers and the percentage of workers in the tunnel 
213 varied greatly (privately informed: $0.6 \%$ to $12.0 \%$; socially informed: $1.9 \%$ to $47.5 \%$,

214 ants in tunnel: $6.0 \%$ to $19.4 \%$; Fig. 5). Furthermore, the use of a quorum would imply

215 that colonies deferred the onset of brood transport on some days for almost one hour

216 after reaching the quorum, while starting to transport just minutes after reaching the

217 quorum on other days (delays for privately informed: 4.3-59.8 minutes; socially

218 informed: 2.8-58.8 minutes; ants in tunnel: 5.4-59.1 minutes). Given that the

219 variability was large for both the quorum threshold and the delay until transport onset,

220 it seems unlikely that a minimum colony level information threshold or a minimum

221 ant proportion in the tunnel needs to be reached for brood transport to be initiated.

222

Night 4
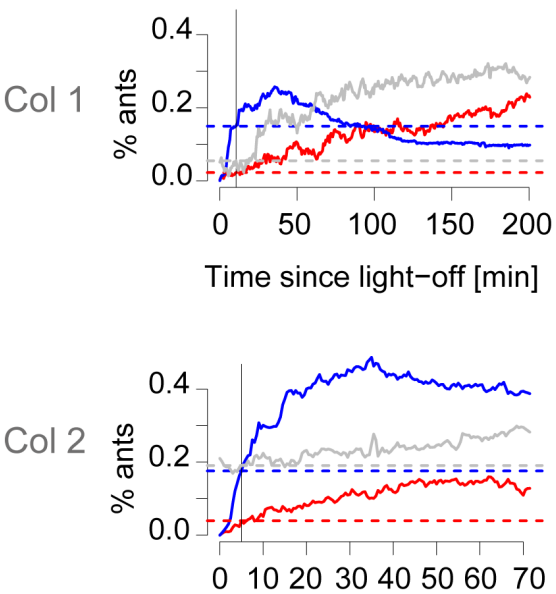

Time since light-off [min]

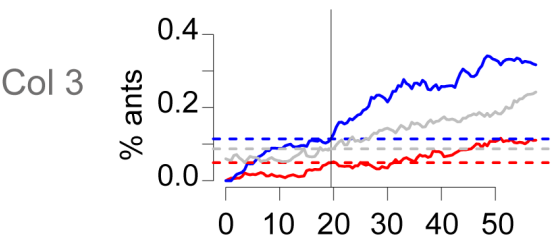

Time since light-off [min]
Night 5
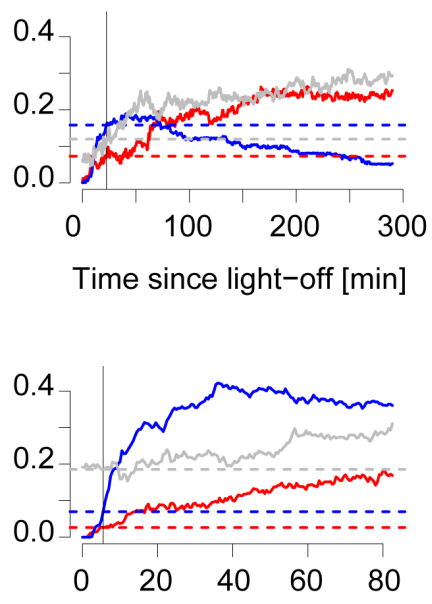

Time since light-off [min]

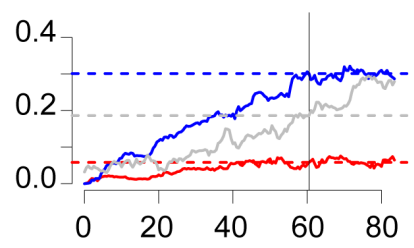

Time since light-off [min]
Night 6
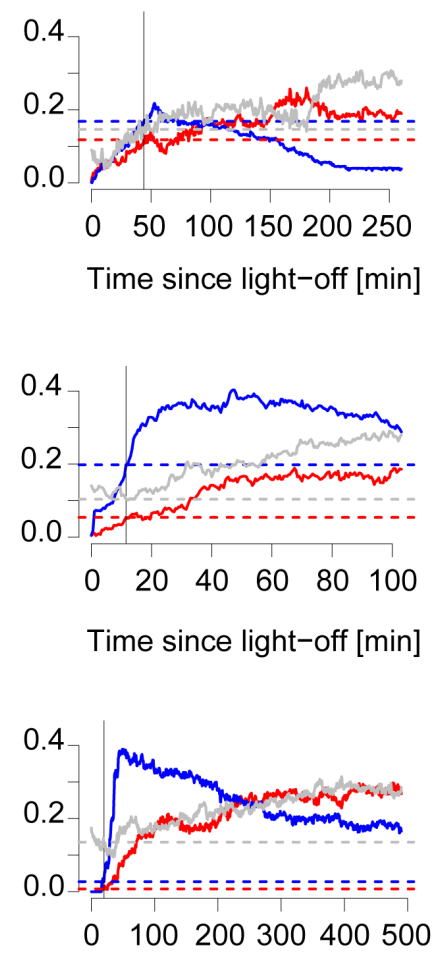

Time since light-off [min]

Fig 5. No evidence for a quorum threshold triggering brood transport. Each line shows the percentage of ants: privately informed ants in red, socially informed ants in blue, ants in the tunnel in grey. The vertical line indicates when the first transport occurred, and the dashed lines highlight the percentages of ants at the time of first transport.

229 Finally, our analyses also revealed high consistency in the direction of brood transport

230 (Supplementary Fig. 5). Overall, there were only 20 return-transports (2.3\%) among 231 the 859 transports recorded. Interestingly, the majority of the workers $(69.2 \%)$ 232 performing return transports did not transport brood to the tunnel while the vast 233 majority (91.7\%) of the workers transporting brood to the tunnel did not perform 
return-transports.

\section{Discussion}

237 The use of an automated system allowed us to obtain detailed and individual-level

238 information on the processes regulating brood transport in response to environmental 239 changes, a process central to the organization of social insect colonies. Overall,

240 workers quickly transported the brood to the preferable location after the light was 241 turned off, and workers almost never transported brood in the wrong direction.

242 However, this seemingly coordinated transport occurred without any detectable sign 243 of communication among workers. While workers frequently interacted, these 244 interactions resulted in no visible change in the behaviour of the transporters, even if 245 the interaction partner had knowledge about the tunnel being dark. Instead, 246 transporters appeared to rely exclusively on self-gathered information, because they 247 initiated brood transport only after having noticed the change of state of the tunnel 248 themselves. Together, these data indicate that synchronised behaviour at the colony 249 level can occur without communication.

251 Visual inspections of our videos also revealed no evidence that workers relied on 252 chemical signals to initiate and communicate brood transport. Transporters never 253 dragged their gaster over the ground, as ants typically do when depositing trails. There 254 were also no instances of worker tandem running, thereby excluding targeted 255 recruitment that could have been mediated by secretions from a gland ${ }^{13}$. The only 256 targeted recruitment that we observed was that of the queen and in one instance that of 257 non-transporting workers (see Supplementary Videos 2, 3). In these cases a worker 258 approached the head of the queen or worker and pulled on her mandibles, with the 259 effect that the pulled ant became active and followed the worker in a tandem-run to 260 the tunnel.

261 The observed lack of communication is likely due to the inherent difficulty of reliably 262 communicating a message in a noisy environment. Communication requires that an 263 informed individual intentionally encodes a message, transmits it successfully, and 264 that an uninformed individual is able to receive it, decode it, and act upon $\mathrm{it}^{29}$. Ants 265 have a limited ability to convey a message through tactile communication alone ${ }^{28,30,31}$. 
266 In addition, the density of workers is extremely high in the nest, resulting in numerous interactions not only with informed individuals but also with uninformed ones. Such a situation leads to a very noisy system where conflicting feedbacks may readily compromise any attempts of communication. Moreover, investing time in recruiting a helper would only beneficial if the time needed for successful recruitment is short, 271 and if recruitment occurs early on (see Figure 6).
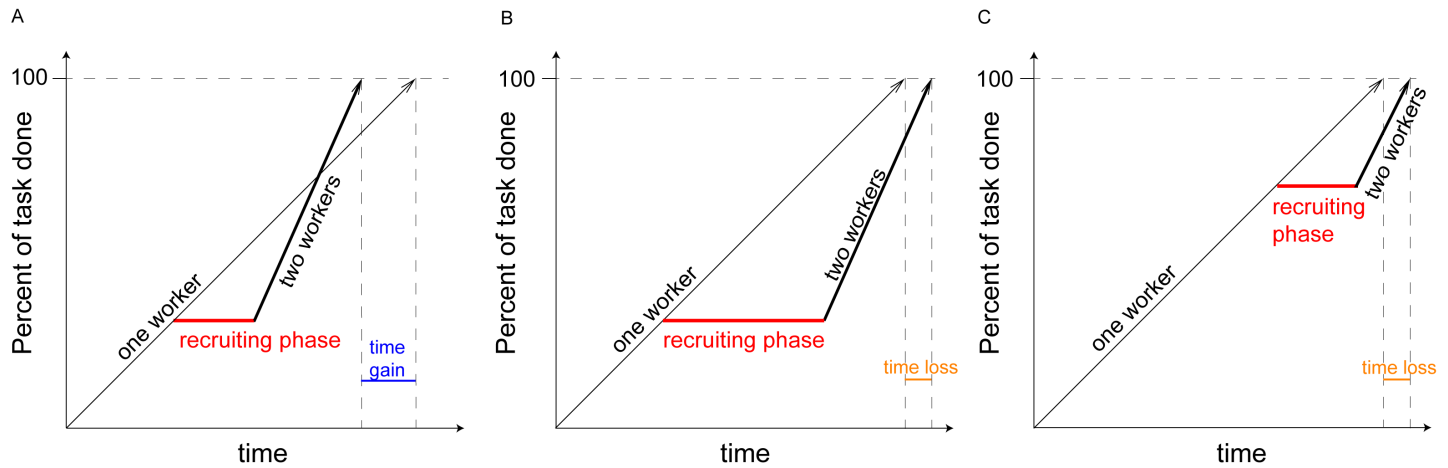

Our observation that transporters check the state of the tunnel themselves, before starting to transport brood, suggests that individual workers gather cues from the environment before deciding to transport brood. The most likely cues used by the transporters in our experiments are the confinement, absence of light and presence of workers in the tunnel ${ }^{32,33}$. The use of cues for decision-making also occurs in other ants, and for processes unrelated to brood transport. For instance, in harvester ants, potential foragers decide whether or not to initiate a foraging trip based on the frequency with which they meet returning foragers ${ }^{34,35}$. Workers of the black garden ant Lasius niger use the chemical profile of the nest wall and their own body size compared to the height of nest pillars as cues to decide whether to switch from wall building to building a roof ${ }^{36}$. These data, together with our results, suggest that the use of cues as a mean to obtain private information might be more widespread and easier to implement in ant colonies than information exchange through tactile 
communication.

296 The use of cues combined with the lack of communication and the absence of a 297 quorum means that transporters most likely decide independently of each other 298 whether, when and where to transport the brood. Such individual-led decisions are 299 further supported by rare instances in which a worker mistakenly returned brood from 300 the tunnel to the nest, while transporters were already moving brood to the tunnel. 301 Interestingly, the vast majority of transporters arrived at the same decision and 302 transported brood from the nest to the tunnel. This strong uniformity in behaviour 303 suggests that there is high homogeneity in preferences among group members.

304 Our results indicate that colonies can display synchronized behaviour without 305 communicating thus emphasizing that not all group-level behaviours in social insects 306 are driven by communication. We suspect that communication is context-dependant 307 and only used when cue-based options are insufficient. For instance, the 308 communication that precedes brood transport in house-hunting ants occurs in the 309 context of an emergency after their nest has been destroyed ${ }^{9,14}$. In contrast, 310 synchronization without communication is optimal when reliable communication is 311 expensive, hard to achieve, or when perfect synchrony is not needed ${ }^{29,37}$. It can be 312 achieved if workers share similar preferences and react to the same cues, which are 313 limited in time. In our experiments light in the tunnel acted as this strong time-limited 314 cue. Synchronized group behaviour exists also in solitary bees, who congregate at 315 nesting sites for reproduction ${ }^{38}$, bats and starlings that converge at seasonal feeding 316 and sleeping spots ${ }^{39,40}$ and Mormon crickets, who migrate in masses in search for salt 317 and proteins ${ }^{41}$. In ants simulations further suggest that food choice during foraging 318 could be achieved without communication through individual learning and 319 preference $^{42}$.

321 Our results also revealed that only a tiny fraction of the individuals, $1.5 \%-6.6 \%$ of the 322 colonies' workforce - as few as three workers in some cases - contributed to brood 323 transport. Moreover, within colonies there was strong variation in the relative 324 contribution of workers with more than $80 \%$ of all transports being carried out by less 325 than $1.8 \%$ of the workers. Similar fractions of transporters and workload disparities 326 were observed in colony emigrations of Formica sanguinea and Camponotus 
sericeus $^{43}$. The large variability in behaviour is puzzling and we offer two possible explanations. There could be specialist nurses that focus on brood transport. Indeed nine out of 48 transporters moved brood every single night and did slightly less than

330 half of the work, thus acting as key individuals ${ }^{44}$ during the brood displacement.

331 Similar specialization has been reported for foraging, brood care, stone 332 collection $^{45,46,47}$ and could result from inherent and consistent differences between 333 workers, for example in motivation, physiology, or sensory threshold ${ }^{48,49}$. Another 334 explanation is that transporters represent a varying subset of the nurses, whose 335 likelihood to transport depends on the individual's state in the early night. This idea is 336 supported by the observation that two thirds of the transporters only worked a single 337 night.

338 Importantly, a small minority of transporters imposed their transport decision on the 339 colony. Such an outcome was only possible because the other workers did not oppose 340 the brood transports or if they did so initially, never persisted in their opposition. 341 Minority-driven behaviour occurs also in Paratrechina longicornis ants, where a 342 single worker can temporarily decide the pull direction during collective transport ${ }^{50}$. 343 Our results therefore highlight that a small minority of the workforce can determine 344 the colony fate through persistent activity in a largely indifferent society. Similar 345 observations exist for fish schools and human crowds where few knowledgeable 346 individuals can lead large groups of uninformed individuals to a new location ${ }^{51,52}$. 347 Ultimately, the social unresponsiveness of the majority might be the optimal strategy 348 because social unresponsiveness can ensure that the colonies react to environmental 349 change while also being robust to noise and avoiding losses in information accuracy 350 resulting from an over-reliance on social information ${ }^{53}$.

352 Acknowledgements. We thank M. Chapuisat, O. Feinerman, N. Stroeymeyt, T.

353 Richardson, T. Kay and S. McGregor for comments on an earlier version, and B.

354 Sutcliffe for proofreading. DPM was supported by a grant from HFSP, JPE was 355 supported by an advanced ERC grant, LK was supported by grants from the Swiss $356 \quad$ NSF and an advanced ERC grant. 
358 Contribution. DPM and LK planned the experiment. DPM and AC designed the experimental system and performed the experiment. DPM and JPE analysed and interpreted the data. DPM wrote the paper with input from JPE and LK. All authors revised the paper.

\section{Material and Methods}

363 The three colonies were each established from a single queen collected after a mating 364 flight in Tel Aviv on March $23^{\text {rd }}$ 2007. The experiment started when queens were 3 365 years old, out of a maximum life span of 26 years $^{54}$. At the start of the experiment, 366 colonies each comprised a queen, brood and 197, 192 and 206 workers, for colonies 1 , 3672 and 3 respectively. The colony sizes were those naturally reached by queens of that 368 age, and reflect normal growth rates in the laboratory; no data are available for field 369 colonies. All workers were the offspring of a single queen, which in Camponotus 370 fellah is usually singly-mated ${ }^{55}$.

371 To determine workers' age, new-born workers were paint-marked on a weekly basis 372 during the 12 months preceding the experiment. Because 38 out of the 45 transporters were nurses, we limited the analysis on the effect of age to nurses only.

375 During experiments colonies were kept in a dark nest chamber connected by a $60 \mathrm{~cm}$

376 long and $1 \mathrm{~cm}$ wide tunnel to a foraging chamber. The tunnel and the foraging box had 377 12h light-12h dark cycles, and the ants had access to food (gelatinous sugary water) 378 and water in the foraging box. The temperature $\left(30^{\circ} \mathrm{C}\right)$, humidity $(60 \%)$, light 379 ( $\sim 500$ Lux), and food supply were computer-controlled, and both chambers were 380 filmed from above with high-resolution monochrome cameras operating under 381 infrared light, as previously described ${ }^{27}$ (Supplementary Fig. 1). All colony members 382 were video-tracked using fiducial identification labels over 14 consecutive days. We 383 recorded the position and orientation of all individuals twice per second.

385 During the night, workers transported the brood to the tunnel and brought it back to the nest at dawn, presumably because they prefer to keep the brood in a confined environment rather than an open environment when both are dark. We tracked the transport of brood items manually during three consecutive nights. A brood transport 
was defined as the time interval from when an ant collected one (or several) brood items from the nest box, to when the ant disappeared with it into the tunnel. We also recorded cases where brood was transported from the tunnel to the nest. In these return-transports, the transport was defined as the time interval from when the ant entered the nest with brood until the ant dropped the brood. For each transporter and each night we defined its workload as the number of transports during that night and its work time as the time from the start of its first transport until the end of its last transport. Using the work times of all workers, we estimated synchrony as the percentage of time during which at least two workers worked in parallel. We also visually inspected the videos for instances of tandem running, that is events where one ant guides another ant to the tunnel. A tandem-run results in successful recruitment if 400 the follower ant subsequently starts transporting brood. We did not track brood 401 transports in the mornings when the lights turned on in the tunnel, because in these conditions all ants in the tunnel were immediately informed of the environmental change, thus making the question of communication inane.

To determine group membership of each worker, i.e. nurse, cleaner or forager, we used the same approach as in Mersch et al. $(2013)^{27}$. In brief, we inferred all social interactions between workers based on their distance and orientation, and analysed the social networks with the Infomap algorithm ${ }^{26}$ to assign each worker to a group. Because the majority of workers were in the tunnel at night and thus undetectable with our tracking setup, we built daily interaction networks using only data collected

411 between $8 \mathrm{am}$ and $7 \mathrm{pm}$, when the majority of workers were detectable.

413 To measure the speed change following interactions, we calculated the speed during 414 the 10 seconds prior to the interaction and during the 10 seconds after the interaction.

415 We included only those interactions for which we had data on the speed before the 416 interaction for both partners and on the speed after the interaction for the focal ant. As 417 a consequence, 50 interactions (10.2\%) were excluded from the analysis. Excluding 418 these interactions had neither an impact on the average duration of an interaction $419(10.5 \pm 29.9 \mathrm{~s} v s .10 .3 \pm 30.5 \mathrm{~s})$ nor on the proportion of interactions with privately 420 informed partners $(7.72 \%$ vs. $7.69 \%)$. To further ensure that our results are not 421 influenced by the chosen interval (10 s), we repeated the same analyses for shorter 
422 (5 s) and longer (20 s) time intervals. Because the results were the same for all time 423 intervals (see Supplementary Table 1), we only report data for the 10-second interval.

425 To investigate whether a privately informed ant can communicate information about 426 the change of state in the tunnel to its interaction partner we estimated the change in 427 trajectory of each worker following its first interaction with a privately informed ant.

428 We calculated the heading of the ant's trajectory after it had moved away from the 429 interaction point, transforming data of all colonies so that an orientation of $0^{\circ}$ 430 corresponds to an orientation towards the nest entrance. We also calculated the 431 distance to the entrance at the time of the interaction and after the ant had moved at 432 least $2 \mathrm{~cm}(\approx$ queen body length) away from the interaction point. Workers who did 433 not interact with a privately informed ant before the end of the brood transport were 434 not included in the analysis (351 out of 1785 ant-days excluded).

436 To estimate how communication about the change of state in the tunnel could modify 437 the trajectory of workers, we generated simulated datasets in which $0 \%, 10 \%, 50 \%$ or $43890 \%$ of the transporters moved toward the nest entrance after interacting with a 439 privately informed ant. Understanding the message meant that one bit - that is, one 440 unit of information - was transferred from the privately informed ant to the 441 transporter. Such one-bit information could convey two options - towards and away 442 from nest entrance - and signal to the transporter to move towards the nest entrance. 443 Each dataset was the average of 66 simulated direction vectors $v j$ defined as

$v_{j}=\left(\cos \left(\alpha_{j}\right), \sin \left(\alpha_{j}\right)\right)$

445 with $\alpha_{j}$ being the angle of the direction relative to the line connecting the interaction 446 point with the nest entrance. For each informed transporter, we randomly chose a 447 direction from a uniform distribution limited to angles between $-\pi / 2$ and $\pi / 2$, for all 448 other transporters we randomly chose an angle from a uniform distribution between $449 \pi$ and $\pi$. We repeated this process 40 times for each information level. We also 450 calculated the average direction of the 66 transporters from the observed data.

452 To test whether a quorum triggered the observed brood transport, we determined the 453 number of ants, the number of informed ants, and the number of ants in the tunnel at 
454 the time of the first brood transport. To estimate whether the quorum induced brood 455 transport, we also calculated the duration between the time the quorum was reached 456 for the first time and the first brood transport. Because the estimated quorum varied 457 between colonies and days, we calculated the delays for all colonies and days using 458 the smallest estimated quorum threshold.

459 We performed all statistical analysis in R (Version 3.4.0) ${ }^{56}$. When the test assumptions 460 were met, we used two-tailed parametric tests and included the colony ID as a random 461 factor in our analysis; otherwise we used non-parametric tests. For statistical tests on 462 colonies, each colony was one replicate. For statistical tests on individual workers, 463 each transporter on each day was a replicate. The data analysis code will be available 464 as a zip file.

465 The data used to prepare all figures and perform statistical tests will be available on 466 Dryad DOI after publication in a journal. Social behaviour in mesopelagic jellyfish. Scientific Reports 5:11310. DOI: 10.1038/srep11310

2. Kiriazis J, Slobodchikoff CN (2006) Perceptual specificity in the alarm calls of Gunnison's prairie dogs. Behavioral Processes. 73:29-35. DOI: 10.1016/j.beproc2006.01.015

3. Rohrseitz K, Tautz J (1999) Honey bee dance communication: Waggle run direction coded in antennal contacts? J Comp Physiol A 184:463-470.

4. von Frisch K. Tanzsprache und Orientierung der Bienen. (Springer Verlag, Heidelberg 1965) 566

5. Conrad L, List C (2009) Group decisions in humans and animals: a survey. Philosophical Transactions of the Royal Society of London B: Biological Sciences 364:719-742. DOI: 10.1098/rstb.2008.0276 
7. Conrad L, Roper TJ (2005) Group decision-making in animals. Nature 421:155-8. DOI: 10.1038/nature01294

8. Seeley TD (2003) Consensus building during nest-site selection in honey bee swarms: the expiration of dissent. Behav Ecol Sociobiol 53:417. DOI: $10.1007 / \mathrm{s} 00265-003-0598-\mathrm{z}$

9. Franks NR, Pratt SC, Mallon EB, Britton NF, Sumpter DJT (2002) Information flow, opinion polling and collective intelligence in house-hunting social insects. Philosophical Transactions of the Royal Society B: Biological Sciences 357:1567-1583.

10. Britton NF, Franks NR, Pratt SC, Seeley TD (2002) Deciding on a new home: how do honeybees agree? Proceedings of the Royal Society of London B: Biological Sciences 269:1383-1388. DOI: 10.1098/rspb.2002.2001

11. Hölldobler B, Wilson EO, The Ants (Springer, Berlin, 1990).

12. Attygalle AB, Morgan ED, Berridge MJ, Treherne JE, Wigglesworth VB. Ant Trail Pheromones, in Advances in Insect Physiology (Academic Press 1985) of signal in ant communication. Science 186:1046-1047. DOI: 10.1126/science.186.4168.1046

14. Stroeymeyt N, Franks NR, Giurfa M (2011) Knowledgeable individuals lead collective decisions in ants. J Exp Biol 214:3046-3054. DOI: $10.1242 /$ jeb.059188

15. Amoore JE, Palmieri G, Wanke E, Blum MS (1969) Ant alarm pheromone activity: Correlation with molecular shape by scanning computer. Science 165 : 1266-1269. DOI: 10.1126/science.165.3899.1266

16. Kadochová S, Frouz J (2013) Thermoregulation strategies in ants in comparison to other social insects, with a focus on Formica rufa. F1000Research 2:280. DOI: 10.12688/f1000research.2-280.v2

17. Abril S, Oliveras J, Gómez C (2010) Effect of Temperature on the Development and Survival of the Argentine Ant, Linepithema humile. J Insect Science 10:97. DOI: 10.1673/031.010.9701 further observations on ants deprived of food. Biological Bulletin 9:361-367. DOI: $10.2307 / 1535632$ 
19. Porter SD (1988) Impact of temperature on colony growth and developmental rates of the ant, Solenopsis invicta. J Insect Physiol 34:1127-1133

20. Porter SD, Tschinkel WR (1993) Fire ant thermal preferences: behavioral control of growth and metabolism. Behav Ecol Sociobiol 32:321-329.

21. Penick CA, Diamond SE, Sanders NJ, Dunn RR (2016) Beyond thermal limits: comprehensive metrics of performance identify key axes of thermal adaptation in ants. Functional Ecology 31:1091-1100. DOI: 10.1111/13652435.12818

22. Steiner A (1929) Temperaturuntersuchungen in Ameisennestern mit Erdkuppeln, im Nest von Formica exsecta Nyl. und in Nestern unter Steinen. Z vergl Physiol 9:1-66.

23. Kay CAR (1978) Preferred temperatures of desert honey ants (Hymenoptera: Formicidae). J Thermal Biol 3:213-217

24. Roces F, Núñez JA (1989) Brood translocation and circadian variation of temperature preference in the ant Camponotus mus. Oecologia 81:33-37. DOI: 10.1007/BF00377006

25. Roces F, Núñez JA (1995) Thermal sensitivity during brood care in workers of two Camponotus ant species: Circadian variation and its ecological correlates. J Insect Physiol 41:659-669. DOI: 10.1016/0022-1910(95)00019-Q

26. Rosvall M, Bergstrom CT (2008) Maps of random walks on complex networks reveal community structure. Proc Natl Acad Sci USA 105:11181123

27. Mersch DP, Crespi A, Keller L (2013) Tracking individuals shows spatial fidelity is a key regulator of ant social organization. Science 340:1090-1093. DOI: $10.1126 /$ science.1234316s

28. Razin N, Eckmann JP, Feinerman O (2013) Desert ants achieve reliable recruitment across noisy interactions. J R Soc Interface 10:20130079. DOI: 10.1098/rsif.2013.0079

29. Maynard-Smith J, Harper D. Animal Signals. 1st ed. Oxford: Oxford University Press; 2003.

30. Hölldobler B (1971) Recruitment Behavior in Camponotus socius (Hym. Formicidae). Z vergl Physiol 75:123-142. 
31. Traniello JFA (1977) Recruitment behavior, orientation, and the organization of foraging in the carpenter ant Camponotus pennsylvanicus degeer (Hymenoptera: Formicidae). Beh Ecol Soc 2:61-79. DOI: 10.1007/BF00299289.

32. Franks NR, Mallon EB, Bray HE, Hamilton MJ, Mischler TC (2003) Strategies for choosing between alternatives with different attributes: exemplified by house-hunting ants. Anim Behav 65:215-223. DOI: 10.1006/anbe.2002.2032.

33. Symonowicz B, Kieruzel M, Szczuka A, Korczyńska J, Wnuk A, Mazurkiewicz PJ, Chiliński M, Godzińska EJ (2005) Behavioral reversion and dark-light choice behavior in workers of the red wood ant Formica polyctena. J Insect Behav 28:245-256. DOI: 10.1007/s10905-015-9496-2.

34. Greene MJ, Gordon DM (2007) Interaction rate informs harvester ant task decisions. Behav Ecol 18:451-455. DOI: 10.1093/beheco/arl105.

35. Pinter-Wollman N, Bala A, Merrell A, Queirolo J, Stumpe MC, Stumpe, Holmes S, Gordon DM (2013) Harvester ants use interactions to regulate forager activation and availability. Anim Behav 86:197-207. DOI: 10.1016/j.anbehav.2013.05.012.

36. Khuong A, Gautrais J, Perna A, Sbaï C, Combe M, Kuntz P, Jost C, Theraulaz G (2016) Stigmergic construction and topochemical information shape ant nest architecture. Proc Natl Acad Sci USA 113:1303-1308. DOI: 10.1073/pnas.1509829113

37. Dostálková I, Špinka M (2007) Synchronization of behaviour in pairs: the role of communication and consequences in timing. Animal Behav 74:1735e1742. DOI:10.1016/j.anbehav.2007.04.014

38. Kierat J, Filipiak M, Szentgyörgyi H, Woyciechowski M (2017) Predation Cues in Solitary bee Nests. Journal of Insect Behavior 30:385-393. DOI: $10.1007 / \mathrm{s} 10905-017-9626-0$

39. Lewis SE (1994) Night Roosting Ecology of Pallid Bats (Antrozous pallidus) in Oregon. The American Midland Naturalist 132: 219-226

40. Caccamise DF, Morrison DW (1986) Avian Communal Roosting: Implications of Diurnal Activity Centers. The American Naturalist 128:191198. DOI: $10.1086 / 284553$ 

forced march for protein and salt. Proc Natl Acad Sci USA 103:4152-4156. DOI: $10.1073 /$ pnas.0508915103

42. Oberhauser FB, Koch A, Czaczkes TJ (2018) Small differences in learning speed for different food qualities can drive efficient collective foraging in ant colonies. bioRxiv preprint. DOI: 10.1101/274209

43. Möglich M, Hölldobler B (1974) Social carrying behavior and division of labor during nest moving in ants. Psyche 81:219-236. DOI: $10.1155 / 1974 / 25763$

44. Robson S, Traniello J. Key individuals and the organisation of labor in ants, in Information Processing in Social Insects (Birkhäuser ed. 1999) pp. 239-259

45. Hammel B, Vollet-Neto A, Menezes C, Nascimento FS, Engels W, Grüter C (2016) Soldiers in a Stingless Bee. The American Naturalist 187:120-129. DOI: $10.1086 / 684192$

46. Dornhaus A (2008) Specialization Does Not Predict Individual Efficiency in an Ant. PLoS Biology 6:e285. DOI: 10.1371/journal.pbio.0060285

47. Robson SKA, Traniello JFA (2002) Transient division of labor and behavioral specialization in the ant Formica schaufussi. Naturwissenschaften 89:128-131

48. Pruitt JN, Keiser CN (2014) The personality types of key catalytic individuals shape colonies' collective behaviour and success. Animal Behav 93:8795.DOI: 10.1016/j.anbehav.2014.04.017

49. Robinson GE (1992) Regulation of Division of Labor in Insect Societies. Annual Review of Entomology 37:637-665. DOI: 10.1146/annurev.en.37.010192.003225 Ant groups optimally amplify the effect of transiently informed individuals. Nature Communications 6: 7729. DOI: 10.1038/ncomms8729

51. Reebs SG (2000) Can a minority of informed leaders determine the foraging movements of a fish shoal? Anim. Behav 59:403-409. DOI:10.1006/anbe.1999.1314.

52. Dyer JRG, Johansson A, Helbing D, Couzin ID, Krause J (2009) Leadership, consensus decision making and collective behaviour in humans. Phil Trans R Soc B 364:781-789. DOI: 10.1098/rstb.2008.0233. 

and the evolution of unresponsiveness in collective systems. J R Soc Interface 12:20140893. DOI: 10.1098/rsif.2014.0893.

619 54. Vonshak M, Shlagman A (2009) A Camponotus fellah queen sets a record for Israeli ant longevity. Isr J Entomology 39: 165-168

55. Mersch DP, La Mendola C, Keller L (2017) Camponotus fellah queens are singly mated. Insect Soc 64:269-276. DOI: 10.1007/s00040-017-0543-1

56. R Core Team (2017) R: A language and environment for statistical computing. project.org/. 
bioRxiv preprint doi: https://doi.org/10.1101/364273; this version posted July 16,2018 . The copyright holder for this preprint (which was

not certified by peer review) is the author/funder, who has granted bioRxiv a license to display the preprint in perpetuity. It is made available under aCC-BY-NC-ND 4.0 International license.

628
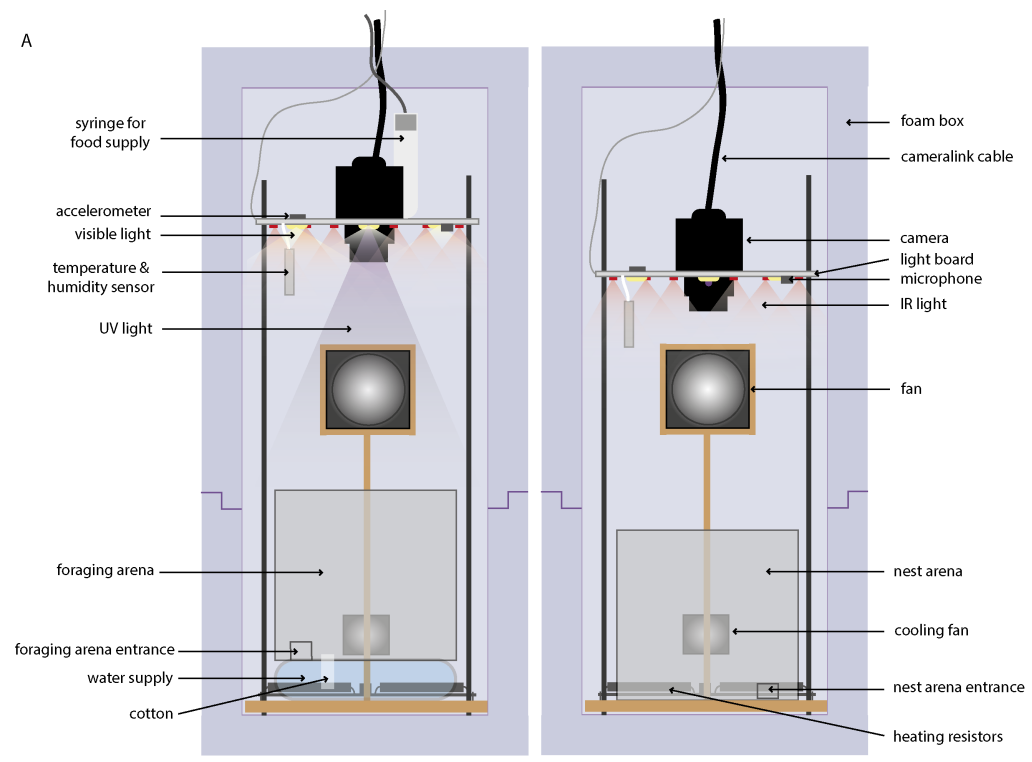

B

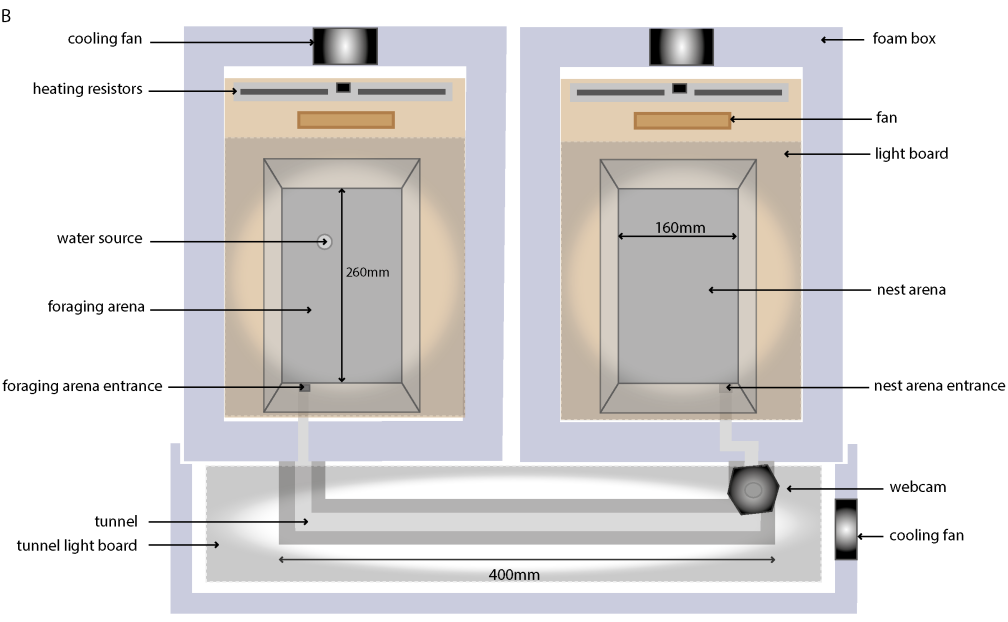

630

631 Supplementary Figure 1: Tracking setup (A) Lateral view (B) Top view; reproduced with 632 permission from Mersch et al. (2013) ${ }^{27}$ 


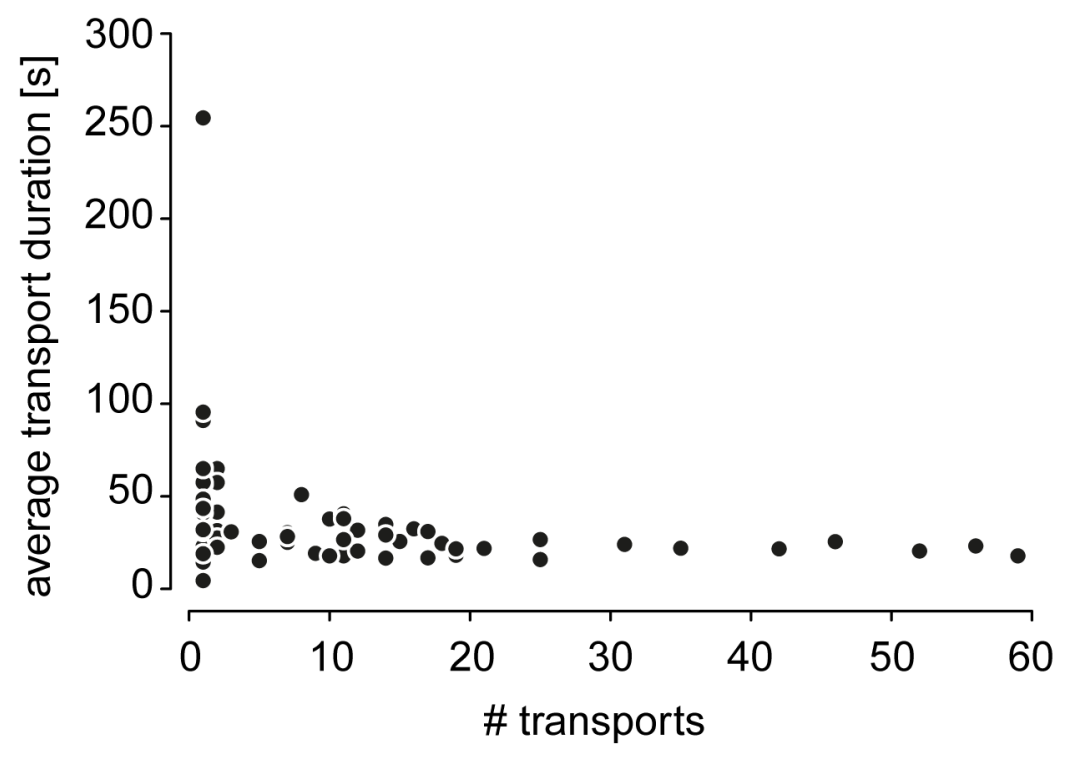

635

636 Supplementary Figure 2. Individual workers transport brood rapidly. Each black dot

637 shows the average transport time needed by a single transporter.

638

639

640 
Night 4

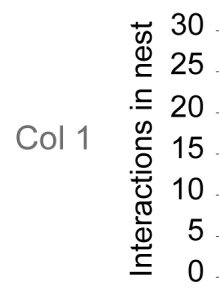
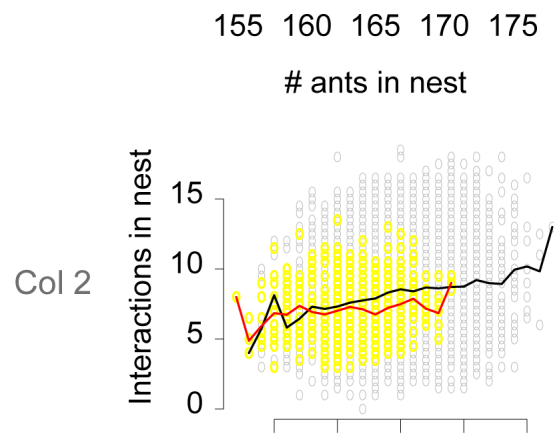

100105110115120

\# ants in nest

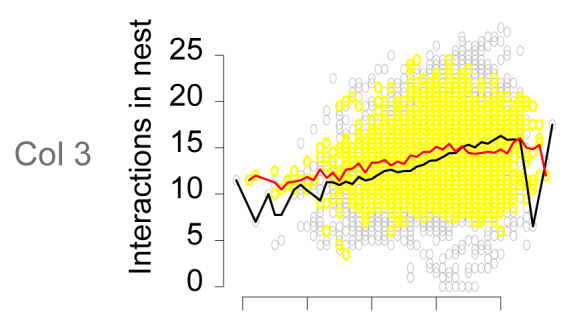

$80 \quad 90100110120$

\# ants in nest
Night 5
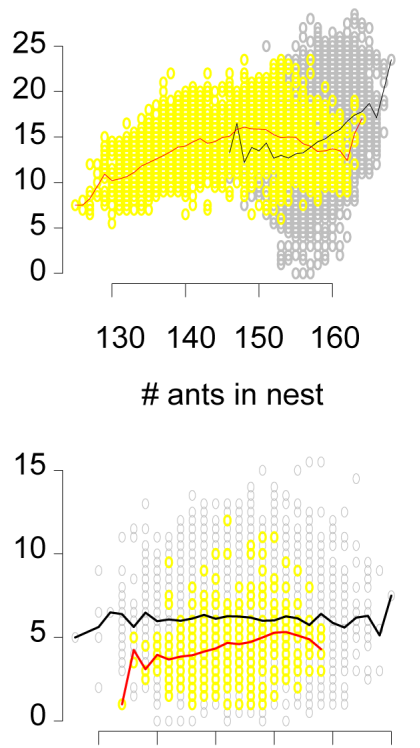

95100105110115120

\# ants in nest

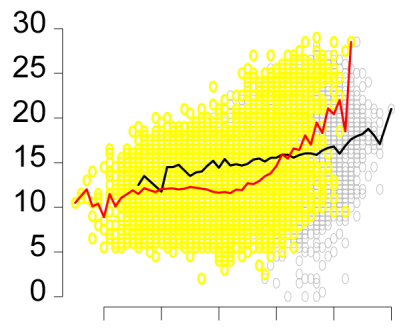

8090100110120130

\# ants in nest
Night 6
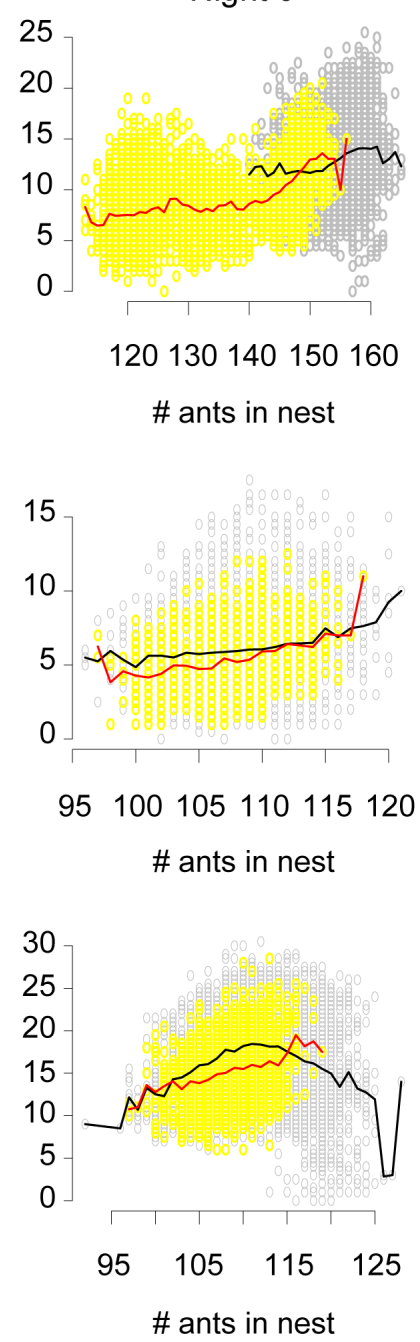

643 Supplementary Figure 3. No change in interaction frequencies after light-off. Grey

644 dots show data in the hour preceding light-off. Yellow dots show data between light-off

645 and the first transport. The black line shows the average relationship between the number

646 of ants in the nest and the number of interactions before light-off, and the red line shows

647 the same relationship in the interval between light-off and the first brood transport. 
A

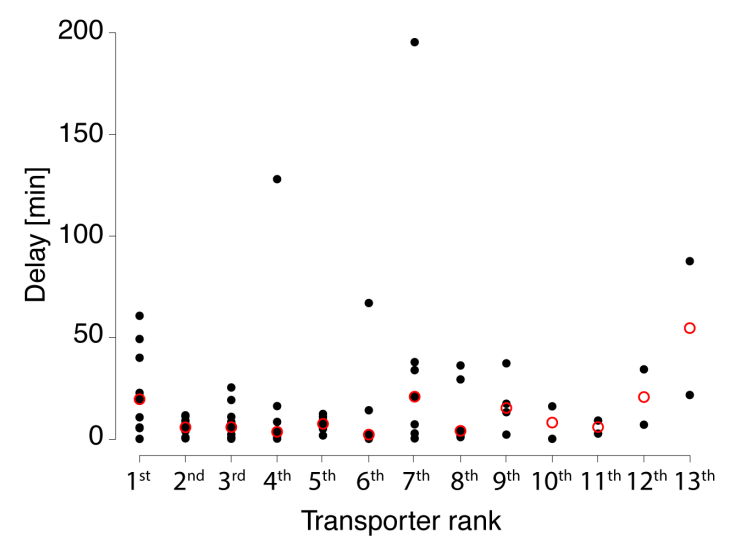

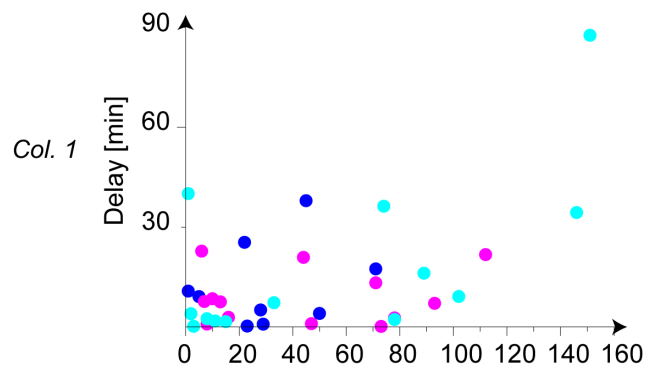
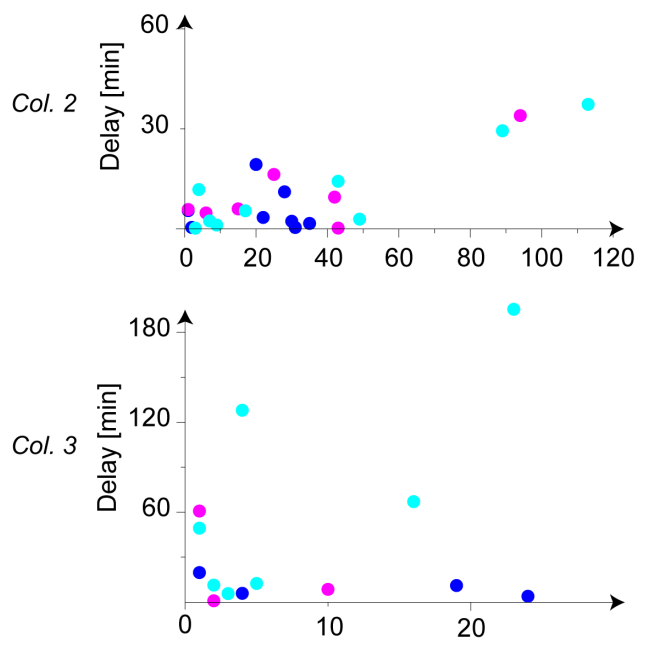

Number of brood items in tunnel

\section{Supplementary Figure 4. Brood accumulation in the tunnel does not speed up}

652 transporter recruitment. A. Each black dot shows the recruitment delay. For all but the

653 first transporter, recruitment delays are with regard to the transport start of the previous

654 transporter. For the first transporter, recruitment delays are with regard to light-off. Red

655 circles indicate the median recruitment delay for each transporter rank. B. The recruitment

656 delays are the same as in A. Blues dots show data for night 4, magenta dots data for night

6575 , and cyan dots data for night 6 . Data are shown separately for each colony. 


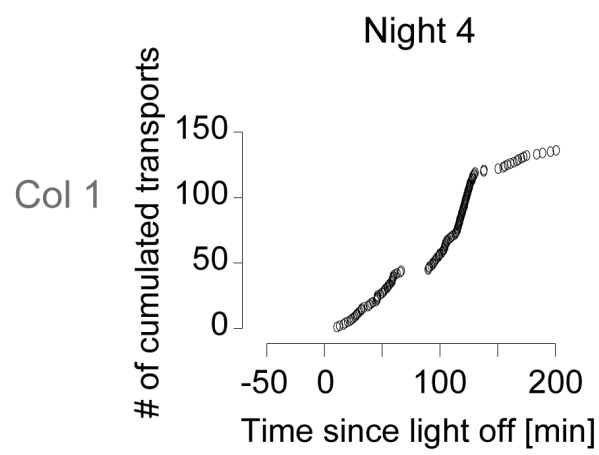

Night 5

Night 6

Time since light off [min]
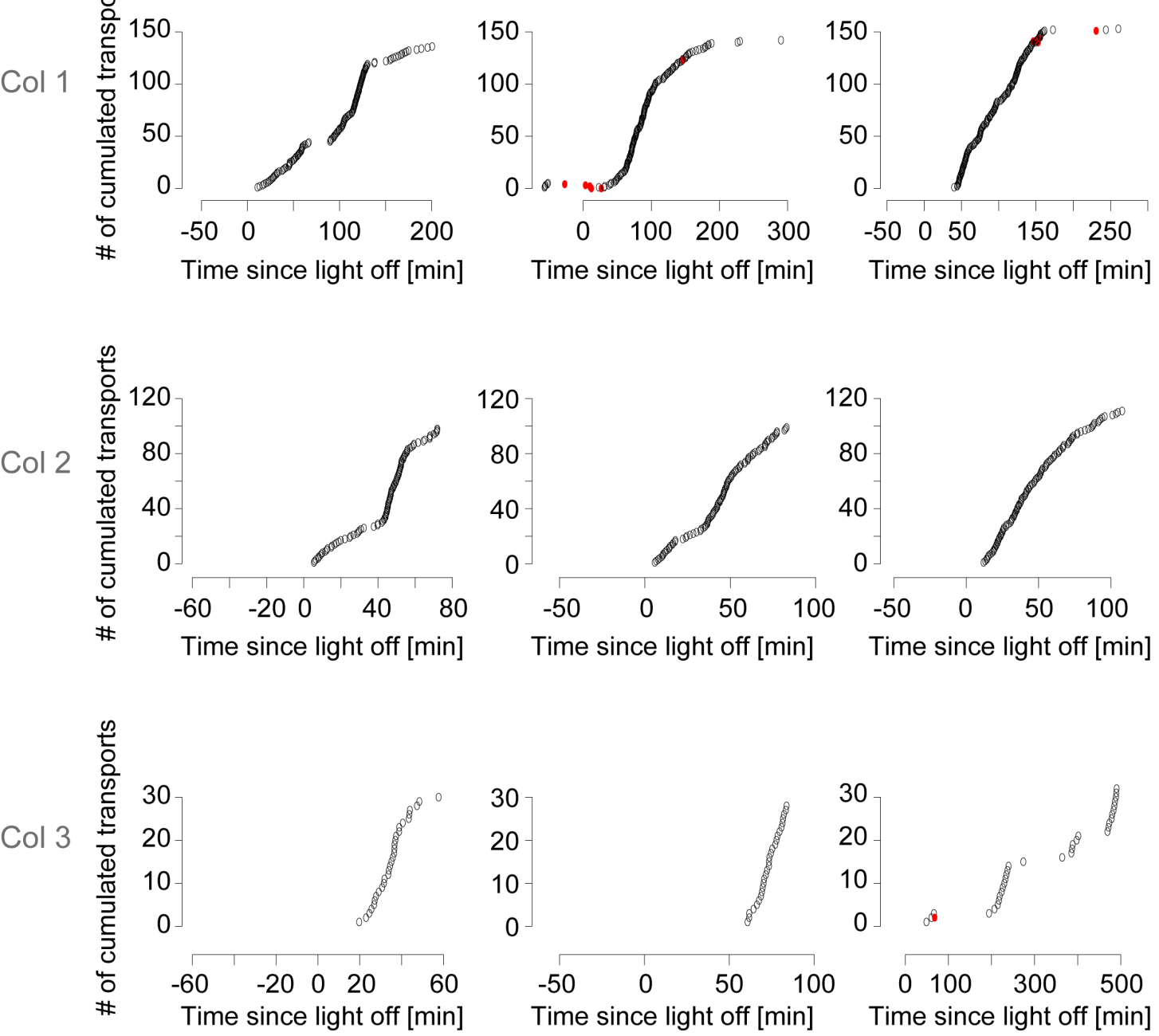

661 Supplementary Figure 5. Workers transport almost exclusively from the nest to the

\begin{tabular}{|r|l|l|l|r|}
\hline $\begin{array}{l}\text { Interval length for } \\
\text { speed estimate (s) }\end{array}$ & $\begin{array}{l}\text { \#interactions excluded due } \\
\text { to missing speed data(\%) }\end{array}$ & $\begin{array}{l}\text { Speed increase after an } \\
\text { interaction with a privately } \\
\text { informed ant (mm/s);mean } \pm \text { std }\end{array}$ & $\begin{array}{l}\text { Speed increase after an } \\
\text { interaction with a non privately } \\
\text { informed ant(mm/s); mean } \pm \text { std }\end{array}$ & $\begin{array}{l}\text { Kruskal-Wallis } \\
\text { Chi2 }\end{array}$ \\
\hline 5 & $79(12.9)$ & $0.89 \pm 2.3$ & $0.26 \pm 3.1$ & \\
\hline -value & $0.15 \pm 2.9$ & 3.25 & 0.071 \\
\hline 10 & $50(10.2)$ & $0.25 \pm 2.8$ & $0.07 \pm 2.3$ & 0.096 \\
\hline 20 & $20(6.3)$ & $0.23 \pm 1.8$ & 0.079 \\
\hline
\end{tabular}

\section{Supplementary Table 1. Speed change after an interaction with a privately informed} ant. 
bioRxiv preprint doi: https://doi.org/10.1101/364273; this version posted July 16,2018 . The copyright holder for this preprint (which was

not certified by peer review) is the author/funder, who has granted bioRxiv a license to display the preprint in perpetuity. It is made available under aCC-BY-NC-ND 4.0 International license.

671 Supplementary Video 1. Worker transporting brood. Worker 62 transports brood to the

672 tunnel. At $16 \mathrm{~s}$ in the video, ant 62 takes brood directly from another worker without this

673 worker changing its behaviour. Data is from colony 2 and the frame rate is accelerated 5

674 times. The green line shows the worker's trajectory in the previous minute.

675

676 Supplementary Video 2. Targeted queen recruitment to the tunnel. Worker 632 (in

677 pink) approaches the queen, pulls on her mandibles, and then returns to the tunnel with

678 the queen (in blue) following her. The data are from colony 1.

679

680 Supplementary Video 3. Recruitment of two non-transporters to the tunnel. Worker

681458 (in green) interacts with workers 607 (in blue) and 278 (in cream), and both then follow

682 worker 458 to the tunnel. The trajectories are shown for all three workers after the 683 interactions finished. The data are from colony 1. 